\title{
Image-based storytelling: a visual narrative of my family's story
}

Cite as: CMAJ 2018 September 17;190:E1112-3. doi: 10.1503/cmaj.180435

See related article at www.cmaj.ca/lookup/doi/10.1503/cmaj.180384

am a member of the Deninu Kue First Nation in Northwest Territories and am applying my interdisciplinary arts background to health care education, writing and painting. My aim is to explore an arts-based thesis on Indigenous perspectives of wellness and the disabling effects of colonialism.

It's important to me to tell my family's story, which encompasses these concerns, but I am reluctant to put the stories into words. As part of an oral culture, I worry about oversimplifying both the context and knowledge illustrated by my images. Ideally, the sharing of images is a relational process, in which the story that accompanies each image is conveyed through oral storytelling. Much of this work is inspired by family experiences, and when I speak their story aloud, they remain free; when I write their story, I fear trapping them in print.

\section{Lisa Boivin BA}

Rehabilitation Sciences Institute, Faculty of Medicine, University of Toronto, Toronto, Ont.

This article has been peer reviewed.

Editor's note: This is part two of an article about Lisa Boivin's approach to bioethics in Indigenous health. The first article can be accessed at www.cmaj.ca/lookup/doi/10.1503/ cmaj.180384.

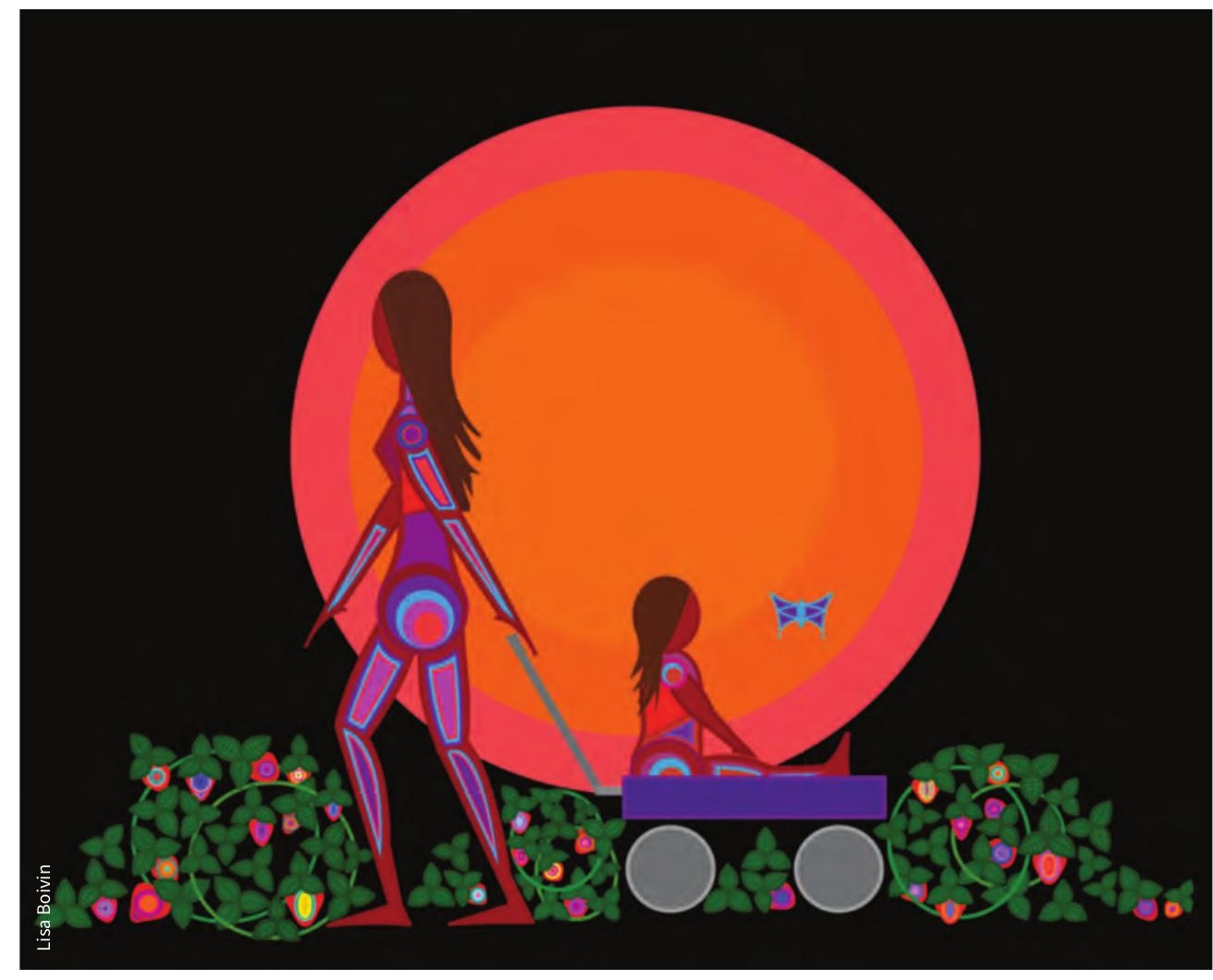

We Had the Entire Day to Ourselves: I think about the relationship my grandmother had with her children. My heart aches for her because all of them were taken to residential school at a very young age. In this painting, my grandmother is with my father when he was a young boy. I am told that she was a warm and engaging woman who doted on her children. My father had polio as a child, and my family used their creativity to increase his mobility so he could participate in day-to-day life. Here my grandmother pulls him in a wagon, and the sun is setting as they return home after a day of play.

I learned from my father that a Dene concept of wellness is more robust than the medical model, which seeks to confirm the presence or absence of disease. Rather, the ability to interact with the land (noting that a Dene worldview encapsulates land as all aspects of life, such as plants, wildlife, community and culture) is the measure of wellness. As such, my father had no concept of being perceived as "unwell" or "disabled" until he was taken from the land and the medical model was thrust upon him in residential school. 


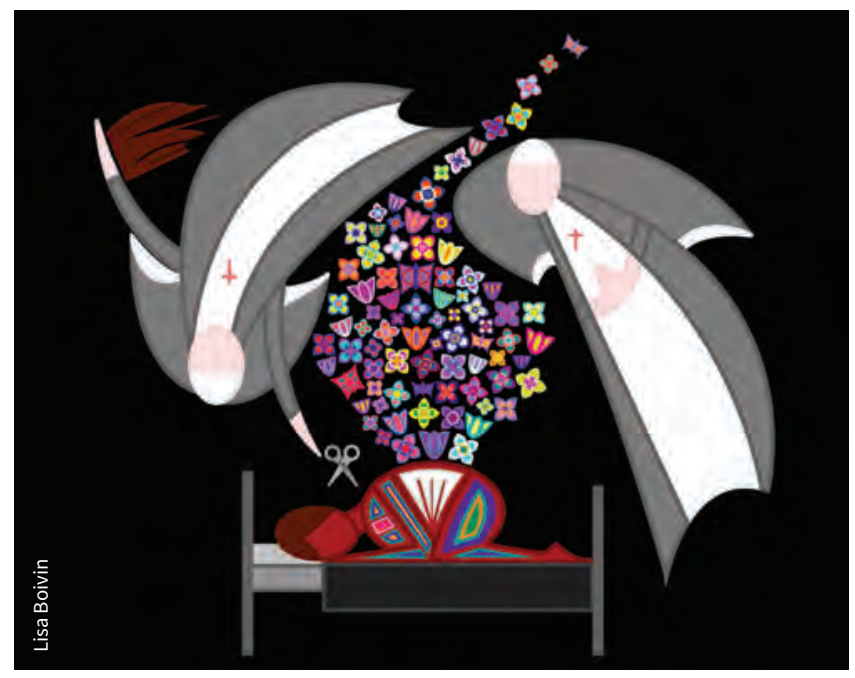

Cutting Away Culture: Severance from land and culture disrupts wellness. Cutting Away Culture shows the colonial violence many children experienced in residential school. It started with a haircut, and was followed by a continual severance from culture. The colonial process is experienced throughout a lifetime. During his stay at residential school, my father was sent away for more than a dozen surgeries. He endured a torturous rehabilitation schedule, all without his mother's consent. From the time he was four years old, clinicians and residential school staff tried to teach him that he couldn't look after himself. This affected all his future clinical interactions.

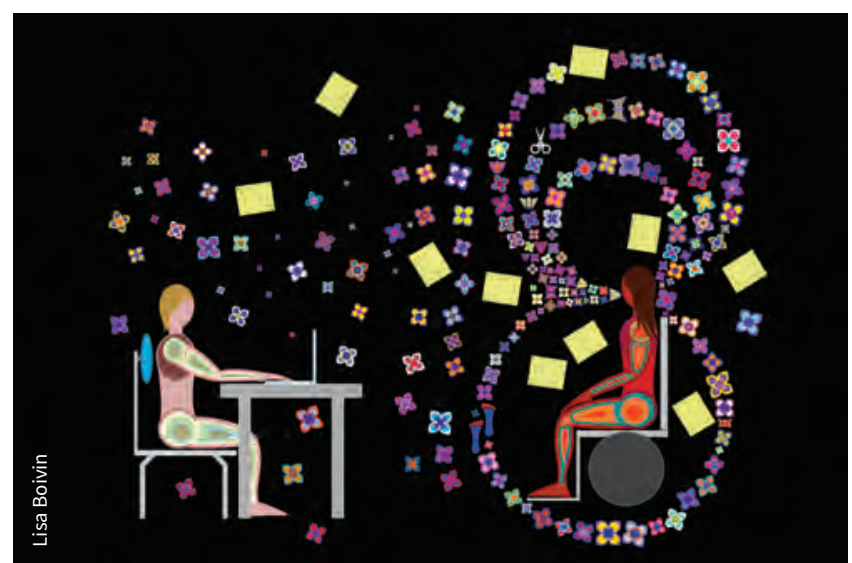

[Untitled]: There is no name for this painting because it is unnameable. Words have power; to give words to something is to give it power. Here my father is making his independent assessment statement, required to receive compensation for years spent attending residential school. He was obliged to detail verbally the colonial indignities he had suffered. This statement is painted as chaos; pages of notes swirl in the image. His wellness was severely affected by being forced to speak those words. Throughout his life, he had varying degrees of mobility. Often he walked with no assistive devices, and other times with a cane; occasionally he required a walker or a wheelchair. After he made this statement, he did not walk again.

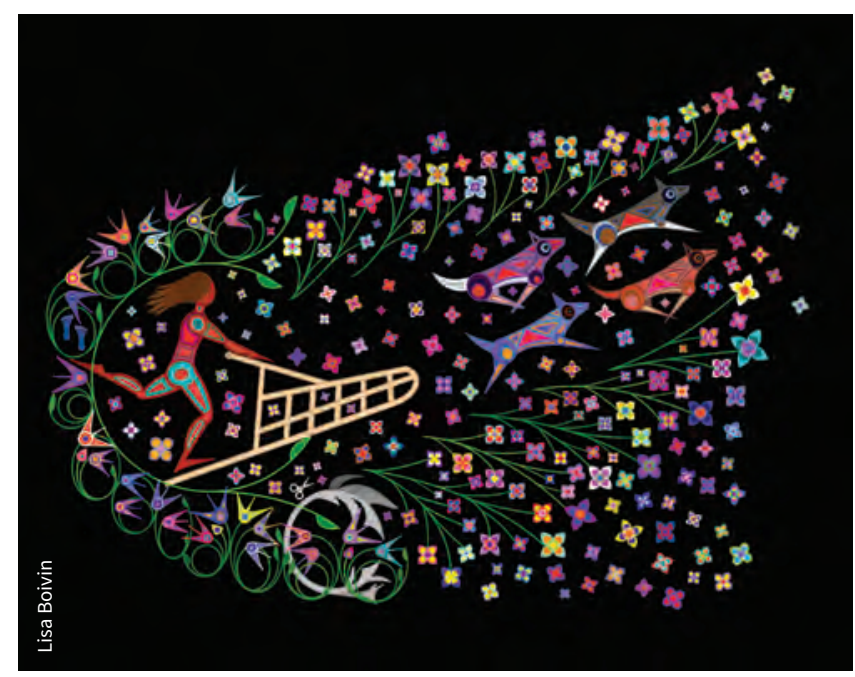

Let the Skyworld Shake: My father rejected all forms of clinical intervention when he returned home from residential school. He got on a dog sled and all was well. He was no longer a "disabled man"; he was simply a Dene man enjoying a life of wellness because he was interacting with the land. Within a year, he was a champion dog musher. Dog sledding requires a tremendous amount of lower body strength. Back on the land, he was not hindered by a medicalized notion of a mobility impairment. This determination was executed in all areas of his life.

At age 65, my father received a diagnosis of pancreatic cancer. In this image I paint the hospital, where he died, as a strange garden in which disease flourishes and carries him afar. Here he powerfully transitions into the Spirit World. Let the clinical flowers fall away. Let the Skyworld Shake, for my father, Little Wolf, is returning home. 